\title{
The role of the immune response in the etiopathogenesis of endometriosis
}

\author{
Catalina Diana Stanica, Adrian Neacsu, Romina Marina Sima, Raluca Gabriela Ioan \\ Department of Obstetrics and Gynecology, "Carol Davila" University of Medicine and Pharmacy, \\ Bucharest, Romania
}

\begin{abstract}
Endometriosis is a benign, chronic, estrogen-dependent condition, present in $10 \%$ of women of reproductive age. The condition is associated with chronic pelvic pain and infertility that influence their quality of life, as well as married life and has important socio-economic consequences.

Despite its high morbidity, its etiopathogenesis is incompletely known. A large number of studies suggest that the ability of endometrial implants to grow in ectopic locations may be correlated with the altered immune response towards the endometriotic tissue. There are enough data to show that immune system mediators, such as cytokines and chemokines, are playing key roles in the onset and olso on progression of endometriosis. There are studies that prove the association between endometriosis and autoimmune diseases.

The present paper aims to investigate the implications of the immune response in the etiopathogenesis of endometriosis. The study of cellular or humoral immunity deficits, the presence of autoantibodies associated with this condition, can facilitate the understanding of the mechanisms that lead to the appearance and spread of endometriosis.

We hope that this information will ultimately provide the basis for the development of new effective approaches in endometriosis management.
\end{abstract}

Keywords: endometriosis, humoral immunity, cellular immunity

\section{INTRODUCTION}

Endometriosis is a benign, chronic, estrogen-dependent gynecological condition, present especially in women of reproductive age, with important implications on their quality of life, married life, but also with special socio-economic consequences through the costs involved in diagnosis and her treatment.

Symptoms of endometriosis often include dysmenorrhea, non-menstrual pelvic pain, and infertility $(1,2)$. The prevalence of asymptomatic endometriosis remains unknown (3). The gold standard for diagnosis is laparoscopy, unfortunately an invasive method (4). The main methods of treating endometriosis include surgical removal of ectopic tissue and/or hormonal treatment to suppress ovarian function with adverse side effects (5).

The etiology of endometriosis is complex but insufficiently known. It appears to be multifactori- al, including ectopic endometrial tissue, altered immunity, unbalanced cell proliferation and apoptosis, aberrant endocrine signaling, and genetic factors $(6,7)$.

The first and most accepted etiopathogenic theory was that of Sampson, according to which retrograde tubal menstrual flow is responsible for endometrial cell transplantation (8). However, menstrual blood reflux is observed in most women, not all of whom are affected by the disease, so endometriosis cannot be explained by reflux alone. Attempts have been made to find other pathophysiological mechanisms involved, many factors being investigated in this regard: hormonal, adhesion molecules, proteolytic enzymes, growth factors, cytokines, immunological, genetic or environmental factors (9).

Immune system abnormalities have been consistently demonstrated in women with endometriosis, a chronic inflammatory response to the pres- 
ence of the ectopic endometrium. The first data in this direction were provided by W.P. Dmowski in the early 1980s. Subsequently, both changes in cellular immunity and humoral immunity were reported in women with endometriosis $(10,11)$.

A lot of immune cell types, including neutrophils, macrophages, dendritic cells, natural killer cells, helper T cells, and B cells are involved in the onset of endometriosis (12-14). Cytokines and chemokines involved in inflammation, angiogenesis, and tissue growth are increased in plasma and peritoneal fluid in women with endometriosis $(15,16)$. It is suspected that this local and systemic inflammatory environment stimulates frequently presented symptoms, including pain and infertility $(17,18)$.

It has also been hypothesized that there is an association between endometriosis and autoimmune diseases $(19,20)$.

Although numerous studies have been conducted in the last 10 years that have made full use of modern research techniques and methods, many of the highlighted phenomena could not be plausibly explained and the links in the immune system with a role in the appearance and spread of lesions are not fully known. endometriosis. We hope that current and future research will identify some of the mechanisms of endometriosis, thus providing us with new therapeutic possibilities.

\section{AIM AND METHOD}

The aim of this paper was to investigate the implications of the immune response in the etiopathogenesis of endometriosis.

We searched in electronic databases (PubMed, Google Scholar) articles and clinical studies published in recent years on the etiopathogenesis of endometriosis, but also the observed associations between endometriosis and autoimmune diseases. We selected only the materials that specify that they went through the peer review procedure.

\section{DYSFUNCTION OF IMMUNE CELLS INVOLVED IN THE ETIOPATHOGENESIS OF ENDOMETRIOSIS}

The etiopathogenesis of endometriosis is complicated by the involvement of biochemical, endocrine, immune and genetic factors. It has not been identified whether immune dysfunction initiates the pathogenesis of endometriosis or is a product of the disease. There currently appears to be a consensus that the immune system of women with endometriosis is impaired (21). Both cellular and humoral immune mediators are aberrantly expressed in the peritoneal fluid and plasma of patients with endometriosis $(22,23)$.

The main consequences of immune deficiency in endometriosis were first summarized by W.P. Dmowski in 1981. He grouped them into systemic or general changes and local, peritoneal changes (24).

The cells involved can be T helper or B lymphocytes, neutrophils, granulocytes, monocytes, macrophages, dendritic cells, natural killer (NK) cells (25). Given the similarity of the reproductive system and the menstrual cycle between the human species and rhesus monkeys, as well as other mammals used as laboratory animals, comparative studies have been performed on them and on women with endometriosis. Studies were also performed on computer models. Women with endometriosis have an altered condition of intraperitoneal immune cells (26). It has been observed that cellular immunity is generally lower in women with endometriosis, especially the activity of $\mathrm{T}$ lymphocytes and natural killer (NK) cells,

TABLE 1. Immunological abnormalities in endometriosis

\begin{tabular}{|c|c|}
\hline Systemic & Peritoneal \\
\hline Increased immunoglobulin production & Endometrial stromal cell proliferation \\
\hline Increased CD4 helper T cell count & Increased cytotoxicity of peritoneal macrophages \\
\hline $\begin{array}{c}\text { Lymphocyte-mediated cytotoxicity deficit against } \\
\text { endometrium }\end{array}$ & Decreased penetration of the pellucid area by sperm \\
\hline Embryotoxic serum factors & Increased sperm phagocytosis by peritoneal macrophages \\
\hline Serum factors that inhibit NK cell activity & Increased cytokine concentration \\
\hline Cellular immunity deficiency & Increased cyclic macrophage activation \\
\hline Altered NK cell activity & Decreased activity of NK cells and lymphocytes \\
\hline Abnormal autoimmune functions & Presence of specific non-organ antibodies \\
\hline Decreased activity of suppressor T cells & Secretion of IL-1 receptor antagonists by peritoneal macrophages \\
\hline
\end{tabular}


while that of macrophages is intensified, especially with regard to the production of cytokines.

Research has shown an alteration of cellular immune mechanisms, demonstrated by decreased intradermal reaction (assessed by the intensity of perivascular lymphocytic infiltration) to endometrial autologous antigens, antigens in which in vitro decreases the blastic transformation of lymphocytes. This may result in decreased immunological clearance of viable endometrial cells migrated into the peritoneal cavity, a phenomenon whose importance in the occurrence of ectopic endometrial implants is contradicted by the possibility of performing autologous transplants of various tissues. This makes it unlikely that cytotoxic capacity will develop in autologous endometrial cells (27).

Natural killer (NK) cells, which have natural cytotoxic activity, are nonT-nonB lymphocytes. They have antitumor and antiviral cytotoxicity properties independent of histocompatibility antigens (28) and act against cells carrying previously unspecified or opsonized target molecules and coverded with antibodies. The decrease in NK cell activity in women with endometriosis is debatable, it is noted by a number of authors (29), especially in association with increased plasma estrogen levels, but also reported in association with smoking, medication or exercise.

The cellular components of the immune system are irregular in patients with endometriosis and, specifically, in patients with infertile endometriosis. NK cells play an important role in pregnancy and placental development (30). They have also been linked to the remodeling of the spiral artery and produce pro-inflammatory cytokines $(31,32)$. An aberrant number of NK cells is linked to pregnancy pathologies, including pre-eclampsia and fetal growth restriction (33-35). Further studies are needed to understand why NK cells do not mature in patients with endometriosis and how it affects fertility.

In women with endometriosis, the frequency of allergic manifestations, autoimmune diseases or neoplasms does not increase significantly compared to normal women, although decreased cell-mediated cytotoxicity appears to be involved in the onset and development of pelvic endometriosis (36). However, under treatment to suppress the activity of endometriotic implants, the efficacy of NK cells and macrophages is significantly improved, which would be an argument in support of this hypothesis. There is controversy regarding the change in the number of NK cells, some studies reporting their decrease, others increase, or not change. Most authors argue in favor of a deficit of qualitative rather than quantitative, with decreased activity of thee cells, which promotes the implantation and proliferation of endometriotic cells $(37,38)$.

Several mechanisms have been proposed to explain the inhibition of NK cell activity in patients with endometriosis. Some studies have shown the inhibitory effects of peritoneal fluid, or serum in women with endometriosis on NK cells, suggesting the involvement of soluble factors $(39,40)$.

The activity of NK cells, macrophages, was also correlated with the stage of endometriosis. Thus, the immunological changes were more severe in the advanced stages of the disease. In the initial stages there is an increase in the number and activity of lymphocytes and other mononuclear cells in the peritoneal fluid, and in the advanced stages there is a sharp decrease, both numerically and functionally. This could explain the rapid spread of endometriotic implants (41).

Regulatory $\mathrm{T}$ cells are altered in patients with endometriosis, which has suggested that they play a role in the pathogenesis of endometriosis and its associated infertility (42). A smaller number of regulatory $\mathrm{T}$ cells were also detected in the eutopic endometrium in studies performed on laboratory animals (43).

There are other important types of immune cells, including macrophages and dendritic cells, associated with inflammation in endometriosis. These cell types are likely to be involved in endometriosis-associated infertility (44). Several studies are needed to delineate the coordinated interactions between different immune cells in promoting and / or resolving the inflammatory cascade and its impact on infertility in patients with endometriosis.

Peritoneal macrophages can be stimulated by the presence of the ectopic endometrium, causing the accentuation of inflammatory processes, with increasing amount of peritoneal fluid and the concentration of prostanoids and growth factors secreted by macrophages in this fluid. The increased number of macrophages in women with endometriosis has been demonstrated (45), by studies that have also shown an increase in their volume by flow-cytometry.

\section{THE ROLE OF HUMORAL IMMUNITY IN ENDOMETRIOSIS}

Humoral immunity factors are cytokines, lysozyme, acute phase reactants, complement and immunoglobulins. Pro-inflammatory chemokines 
and cytokines such as TNF- $\alpha$, IL-1 $\beta$, IL-6, IL-8, IL-10, IL-17, IL-33, IP-10, MCP-1 MIF and RANTES are expressed aberrantly in peritoneal fluid and plasma in women with endometriosis (46-48). They are involved in inflammation, angiogenesis and tissue growth $(49,50)$. This local and systemic inflammatory environment is suspected to stimulate common symptoms, including pain and infertility $(51,52)$.

By radioimmunological determinations, the study of prostanoid metabolites - prostaglandin derivatives 6-keto-PGF1 $\alpha$ and TxB2, showed their increased values in women with endometriosis (53). It has been demonstrated in vitro cultures that active endometrial tissue produces such substances (prostacyclin, thromboxane).

Prostaglandin substances present in the peritoneal fluid in increased amounts in women with endometriosis would explain the appearance of sterility in those with permeable tubes by altering tubal motility and sperm motility, increasing their phagocytosis, inhibiting fertilization or nesting (54).

Macrophages can stimulate the growth of endometrial cells by secreting growth factors, angiogenetic factors (epidermal growth factor, growth factor derived from macrophages, fibronectin, integrin-adhesion molecules) (55). However, some authors have stated that these changes are the consequence of endometriosis and not its cause, being in fact part of the inflammatory process determined by the presence of ectopic endometrial tissue and its cyclic activity. So, endometriosis would be a disruptive factor of the local biosystem.

Many of these cytokines secreted by competent immune cells have been studied in recent years to establish their role in the pathogenesis of endometriosis. The results are contradictory. It is necessary to study many of these mechanisms in the future.

Interleukin-1 is the most important proinflammatory cytokine and is produced mainly by monocytes / macrophages (56) and has a central role in regulating the immune and inflammatory response. It determines the activation of $\mathrm{T}$ lymphocytes and the differentiation of B lymphocytes. Stimulation of these receptors induces an angiogenic phenotype in endometriotic lesions by increasing the transcription of angiogenic factors (endothelial vascular growth factor and IL-6) $(57,58)$.

IL-33 is a member of the cytokines of the IL-1 family that stimulate different cell types, such as Th2 cells, mast cells and innate lymphoid cells of group 2 (ILC2), and has pleiotropic functions
$(59,60)$. Different cell types, such as epithelial cells and endothelial cells, express IL-33 in the nucleus and release it in response to cellular stress (61). In general, member cytokines of the IL-1 family, including IL-1 $\beta$ and IL-18, are synthesized as precursor proteins in the cytoplasm and become active after processing into inflammation. In contrast, the complete form of IL-33 is active and the protease processing improves its activity, while the caspase cleavage abrogates its function (62). IL-33 is important for innate mucosal immunity in the lungs and intestines and airway inflammation, as well as peripheral antigen-specific responses by inducing Th2 cytokines (63).

Other studies have proposed another mechanism to explain the involvement of IL- $1 \beta$ receptors in the pathophysiology of endometriosis. They reported an increase in soluble adhesive molecules of ICAM-1 after stimulation of these receptors in ectopic endometrial cells, which interferes with immune surveillance mechanisms and allows the tubular reflux endometrium to escape immune clearance from the peritoneal cavity (64).

Interleukin 6 (IL-6) is a $25 \mathrm{kDa}$ glycoprotein, synthesized by macrophages, endothelial cells, vascular smooth muscle fibers, epithelial and stromal endometrial cells. Like IL-1, IL-6 modulates the secretion of other cytokines, amplifies the activation of T lymphocytes and the differentiation of B lymphocytes, and inhibits the growth of various human cell lines, thus being a mitogenic inhibitor (65). Estrogens, through the stimulating role of cell proliferation, inhibit the synthesis of this mitogenic inhibitor, which may explain the effect of growth on endometrial implants. Some authors have suggested that the lack of effect of IL-6 on endometriotic implants is due to decreased expression of receptors for this cytokine on the surface of ectopic endometrial cells (66).

\section{INTERACTION BETWEEN ENDOCRINE AND INFLAMMATORY PATHWAYS}

New evidence suggests that endometriotic lesions themselves produce estrogen (67). This feeding loop creates countless cell signaling cascades in the peritoneal microenvironment. In patients with endometriosis, both eutopic and ectopic endometrial tissue are still involved in excessive estrogen production. In addition, prostaglandin E2 (PGE2) synthesis is induced in the presence of growth factors and pro-inflammatory cytokines, including IL- $1 \beta$, TNF- $\alpha$, IFN- $\gamma$ and IL-17. The production of prostaglandins and cytokines has 
been suggested to facilitate infertility in women with endometriosis (68). Also, the expression of estrogen (ER) and progesterone (PR) receptors is altered by inflammation. Specifically, aberrant expression of ER and PR has been associated with overexpression of IL-1, IL-6 and TNF- $\alpha$ (69). TNF- $\alpha$ and IL- $1 \beta$ have been shown to be elevated in peritoneal fluid in women with endometriosis (70). Other studies have shown that TNF- $\alpha$ decreases estrogen receptor expression in endometrial stromal cells isolated from women with endometriosis (71). The evidence presented demonstrates not only that the aberrant expression of PR and ER is correlated with an increase in inflammatory mediators, but also that inflammation can directly alter their expression.

\section{THE LINK BETWEEN AUTOIMMUNITY AND ENDOMETRIOSIS}

Another intensely studied cytokine is RANTES (regulated on normal T-cell activation expressed and secreted). It exerts a chemoattraction effect on monocytes, memory $\mathrm{T}$ cells and eosinophils. Its secretion in the endometrium is ensured by the stromal compartment (72) in the presence of proinflammatory cytokines. Some studies have shown the presence of high concentrations of this protein in peritoneal fluid in women with endometriosis (73), which amplifies the recruitment of T lymphocytes and macrophages and increases the chemotactic activity of monocytes locally (74).

Elevated concentrations of pelvic macrophages and activated lymphocytes, as well as elevated levels of specific cytokines and growth factors presented above support the hypothesis of the involvement of normal or altered immune mechanisms in endometriosis. Whether these components of inherited or acquired immunity have a primary role in the production of endometriosis or is only a passive reaction to the presence of the ectopic endometrium is not very clear yet, and it remains for future studies to specify this.

Another interesting hypothesis proved to be the involvement of autoimmune phenomena in endometriosis. This has been suggested by the existence of autoantibodies (antiphospholipids, antihistones, antiendometrials etc.) in high concentrations in women with endometriosis.

Endometriosis has common features with other autoimmune diseases, such as rheumatoid arthritis, Crohn's disease, psoriasis: intense inflammatory process, increased levels of tissue remodeling compounds and local and systemic cytokines, altered apoptosis (75).

Many studies have investigated the (auto) immunological pathology of endometriosis and provided consistent evidence of the criteria for endometriosis to fall into the category of autoimmune diseases (76). However, there is little understanding of the common biological pathways between endometriosis and autoimmune diseases that would explain increased comorbidity.

Studies have shown an escape of cells from immune surveillance by analysis of the peritoneal environment in endometriosis (77). Abnormalities have been identified in almost all immune cell types, including elevated levels of peritoneal neutrophils and macrophages, reduced cytotoxic function of natural killer cells, and an aberrant number of $\mathrm{T}$ and $\mathrm{B}$ lymphocytes that help endometriotic cell growth, maintenance, invasion, and angiogenesis (78).

There is evidence of elevated levels of autoantibodies in women with endometriosis. This led to the investigation of their potential role as biomarkers for endometriosis. A recent series of Cochrane reviews of blood biomarkers and urinary biomarkers for endometriosis found that although more antibodies were found to increase in women with endometriosis, only anti-endometrial antibodies and interleukin- 6 were found to be useful for endometriosis. detection of endometriosis Their accuracy cannot yet replace standard surgical diagnosis $(79,80)$. A number of studies of endometriosis candidate genes have been performed to investigate the association between autoimmune genes and endometriosis (81). HLA alleles that are most commonly associated with autoimmune diseases have been reported to be associated with endometriosis (82).

Thus, endometriosis is associated with a polyclonal activation of B lymphocytes, with abnormalities in the immune function of $\mathrm{B}$ and $\mathrm{T}$ cells, increased apoptosis, tissue damage, multiorgan damage, family incidence, possible genetic bases, involvement of environmental factors and is associated with other autoimmune diseases. The relationship between enometriosis-infertility and endometriosis-recurrent abortion can also be explained by the presence of abnormal autoantibodies. Treatment with Danazol or GnRH analogues also lowers the level of autoantibodies associated with endometriosis. Currently, almost all drugs for the treatment of endometriosis are suppressive, not curative. Medical therapy with nonsteroidal anti-inflammatory drugs (NSAIDs), oral 
contraceptives or anti-gonadotropin ensures effective pain relief (83), but not the cure of endometriosis (84), and after medical or surgical treatment, there is a high frequency of recurrence of the disease: $21.5 \%$ at 2 years and $40-50 \%$ at 5 years (85).

Evidence based on observational studies suggests an increased risk of comorbidity of autoimmune diseases in endometriosis. Most endometriosis studies include women of childbearing age, but longer follow-up studies are needed to determine the true risk of autoimmune diseases that may occur after menopause. Larger follow-up studies would help to understand whether endometriosis is a risk factor, or a consequence of autoimmune diseases, or whether these two types of disorders have pathological mechanisms and common pathways. Genetic and biological studies and immunological dysfunctions in the context of endometriosis can improve the understanding of the pathogenesis of both diseases leading to the discovery of new methods of diagnosis and treatment of these diseases.

\section{CONCLUSIONS}

In this paper, we have provided information on the implications of this dysfunction, to understand how the immune system is potentially dysfunctional in patients with endometriosis.

It can be concluded that there is a complex network of local and systemic cytokines that modu- late the inflammatory process in endometriosis, including implant proliferation and invasiveness, new capillary formation and lesion expansion, and chemoattraction of new immune cells in peritoneal foci. However, it remains unclear how immune dysfunction contributes to the pathogenesis of endometriosis. Subsequent understanding of the mechanisms and complex interaction between the immune-endocrine axis can help to understand the heterogeneity of the symptoms observed and can stimulate the process of developing a more comprehensive and precise classification system.

A solid quantification of the association between endometriosis and autoimmune diseases could facilitate the understanding of the causes and consequences of both disorders, especially on the question of whether endometriosis is associated with immunological disorders. Also, given that current medication for endometriosis is primarily a hormonal treatment with considerable side effects due to interference with estrogen levels, such evidence could help provide the benchmark for better medical practices by discovering new drug targets, such as immuno-modulators and the development of new diagnostic tools for endometriosis.

Future research on new therapeutic modalities should seek to understand the mediators of inflammation and the links in the pathophysiological chain of immunological changes, in an attempt to influence the evolution of the disease.

\section{REFERENCES}

1. Agarwal SK, Chapron C, Giudice LC, Laufer MR, Leyland N, Missmer SA, Singh SS, Taylor HS. Clinical diagnosis of endometriosis: a call to action. Am J Obstet Gynecol. 2019 Apr;220(4):354.e1-354.e12.

2. Bazot M, Daraï E. Diagnosis of deep endometriosis: clinical examination, ultrasonography, magnetic resonance imaging, and other techniques. Fertil Steril. 2017 Dec;108(6):886-894.

3. Chapron C, Vannuccini S, Santulli P, Abrão MS, Carmona F, Fraser IS, Gordts S, Guo SW, Just PA, Noël JC, Pistofidis G, Van den Bosch T, Petraglia F. Diagnosing adenomyosis: an integrated clinical and imaging approach. Hum Reprod Update. 2020 Apr 15;26(3):392-411.

4. Kiesel L, Sourouni M. Diagnosis of endometriosis in the 21 st century. Climacteric. 2019 Jun;22(3):296-302.

5. Falcone T, Flyckt R. Clinical Management of Endometriosis. Obstet Gynecol. 2018 Mar;131(3):557-571.

6. Asghari S, Valizadeh A, Aghebati-Maleki L, Nouri M, Yousefi M. Endometriosis: Perspective, lights, and shadows of etiology. Biomed Pharmacother. 2018 Oct;106:163-174.

7. Parazzini F, Esposito G, Tozzi L, Noli S, Bianchi S. Epidemiology of endometriosis and its comorbidities. Eur J Obstet Gynecol Reprod Biol. 2017 Feb;209:3-7.

8. Sampson JA. Metastatic or Embolic Endometriosis, due to the Menstrual Dissemination of Endometrial Tissue into the Venous Circulation. Am J Pathol. 1927 Mar;3(2):93-110.43.

9. Laganà AS, Garzon S, Götte M, Viganò P, Franchi M, Ghezzi F, Martin DC. The Pathogenesis of Endometriosis: Molecular and Cell Biology Insights. Int J Mol Sci. 2019 Nov 10;20(22):5615.

10. Paul Dmowski W, Braun DP. Immunology of endometriosis. Best Pract Res Clin Obstet Gynaecol. 2004 Apr;18(2):245-63

11. Miller JE, Ahn SH, Monsanto SP, Khalaj K, Koti M, Tayade C. Implications of immune dysfunction on endometriosis associated infertility. Oncotarget. 2017 Jan 24;8(4):7138-7147

12. Jeung I, Cheon K, Kim MR. Decreased Cytotoxicity of Peripheral and Peritoneal Natural Killer Cell in Endometriosis. Biomed Res Int. 2016;2016:2916070.

13. Schulke L, Berbic M, Manconi F, Tokushige N, Markham R, Fraser IS. Dendritic cell populations in the eutopic and ectopic endometrium of women with endometriosis. Hum Reprod. 2009 Jul;24(7):1695-703.

14. Xiao F, Liu X, Guo SW. Platelets and Regulatory T Cells May Induce a Type 2 Immunity That Is Conducive to the Progression and Fibrogenesis of Endometriosis. Front Immunol. 2020 Dec 14:11:610963.

15. Braza-Boïls A, Gilabert-Estellés J, Ramón LA, Gilabert J, MaríAlexandre J, Chirivella M, España F, Estellés A. Peritoneal fluid reduces angiogenesis-related microRNA expression in cell cultures of endometrial and endometriotic tissues from women with endometriosis. PLoS One. 2013 Apr 19;8(4):e62370.

16. Nanda A, K T, Banerjee P, Dutta M, Wangdi T, Sharma P, Chaudhury K, Jana SK. Cytokines, Angiogenesis, and Extracellular Matrix Degradation are Augmented by Oxidative Stress in Endometriosis. Ann Lab Med. 2020 Sep;40(5):390-397.

17. Yan D, Liu X, Guo SW. Nerve fibers and endometriotic lesions: partners in crime in inflicting pains in women with endometriosis. Eur J Obstet Gynecol Reprod Biol. 2017 Feb;209:14-24. 
18. Machairiotis N, Vasilakaki S, Thomakos N. Inflammatory Mediators and Pain in Endometriosis: A Systematic Review. Biomedicines. 2021 Jan 8;9(1):54.

19. Shigesi N, Kvaskoff M, Kirtley S, Feng Q, Fang H, Knight JC, Missmer SA, Rahmioglu N, Zondervan KT, Becker CM. The association between endometriosis and autoimmune diseases: a systematic review and meta-analysis. Hum Reprod Update. $2019 \mathrm{Jul}$ 1;25(4):486-503.

20. Zhang T, De Carolis C, Man GCW, Wang CC. The link between immunity, autoimmunity and endometriosis: a literature update. Autoimmun Rev. 2018 Oct;17(10):945-955

21. Zhou WJ, Yang HL, Shao J, Mei J, Chang KK, Zhu R, Li MQ. Anti-inflammatory cytokines in endometriosis. Cell Mol Life Sci. 2019 Jun;76(11):2111-2132.

22. Ścieżyńska A, Komorowski M, Soszyńska M, Malejczyk J. NK Cells as Potential Targets for Immunotherapy in Endometriosis. J Clin Med. 2019 Sep 14;8(9):1468.

23. Moon JM, Chung YJ, Chae B, Kang HJ, Cho HH, Kim JH, Kim MR. Effect of mistletoe on endometrial stromal cell survival and vascular endothelial growth factor expression in patients with endometriosis. Int J Med Sci. 2018 Oct 20;15(13):1530-1536.

24. Dmowski WP, Steele RW, Baker GF. Deficient cellular immunity in endometriosis. Am J Obstet Gynecol. 1981 Oct 15;141(4):377-83.

25. Symons LK, Miller JE, Kay VR, Marks RM, Liblik K, Koti M, Tayade C. The Immunopathophysiology of Endometriosis. Trends Mol Med. 2018 Sep;24(9):748-762

26. Tariverdian N, Siedentopf F, Rücke M, Blois SM, Klapp BF, Kentenich $\mathrm{H}$, Arck PC. Intraperitoneal immune cell status in infertile women with and without endometriosis. J Reprod Immunol. 2009 Jun; 80(1-2):80-90.

27. Vallvé-Juanico J, Houshdaran S, Giudice LC. The endometrial immune environment of women with endometriosis. Hum Reprod Update. 2019 Sep 11;25(5):564-591.

28. Rijkers GT, Damoiseaux JG, Hooijkaas H. Medical immunology: two-way bridge connecting bench and bedside. Immunol Lett. 2014 Dec;162(2 Pt B):127-33.

29. Chou YC, Chen CH, Chen MJ, Chang CW, Chen PH, Yu MH, Chen YJ, Tsai EM, Yang PS, Lin SY, Tzeng CR. Killer cell immunoglobulinlike receptors (KIR) and human leukocyte antigen-C (HLA-C) allorecognition patterns in women with endometriosis. Sci Rep. 2020 Mar 17;10(1):4897.

30. Acar N, Ustunel I, Demir R. Uterine natural killer (uNK) cells and their missions during pregnancy: a review. Acta Histochem. 2011 Feb;113(2):82-91.

31. Shen HH, Zhang T, Yang HL, Lai ZZ, Zhou WJ, Mei J, Shi JW, Zhu R, Xu FY, Li DJ, Ye JF, Li MQ. Ovarian hormones-autophagy-immunity axis in menstruation and endometriosis. Theranostics. 2021 Jan 19;11(7):3512-3526.

32. Kwak-Kim J, Bao S, Lee SK, Kim JW, Gilman-Sachs A. Immunological modes of pregnancy loss: inflammation, immune effectors, and stress. Am J Reprod Immunol. 2014 Aug;72(2):129-40.

33. Cartwright JE, James-Allan L, Buckley RJ, Wallace AE. The role of decidual NK cells in pregnancies with impaired vascular remodelling. J Reprod Immunol. 2017 Feb;119:81-84.

34. Freitag N, Pour SJ, Fehm TN, Toth B, Markert UR, Weber M, Togawa R, Kruessel JS, Baston-Buest DM, Bielfeld AP. Are uterine natural killer and plasma cells in infertility patients associated with endometriosis, repeated implantation failure, or recurrent pregnancy loss? Arch Gynecol Obstet. 2020 Dec;302(6):1487-1494.

35. Glover LE, Crosby D, Thiruchelvam U, Harmon C, Chorcora CN, Wingfield MB, O'Farrelly $\mathrm{C}$. Uterine natural killer cell progenitor populations predict successful implantation in women with endometriosis-associated infertility. Am J Reprod Immunol. 2018 Mar;79(3).

36. Thiruchelvam U, Wingfield M, O'Farrelly C. Natural Killer Cells: Key Players in Endometriosis. Am J Reprod Immunol. 2015 Oct; 74(4):291-301.

37. Riccio LDGC, Santulli P, Marcellin L, Abrão MS, Batteux F, Chapron C. Immunology of endometriosis. Best Pract Res Clin Obstet Gynaecol. 2018 Jul;50:39-49.
38. Izumi G, Koga K, Takamura M, Makabe T, Satake E, Takeuchi A, Taguchi A, Urata Y, Fujii T, Osuga Y. Involvement of immune cells in the pathogenesis of endometriosis. J Obstet Gynaecol Res. 2018 Feb;44(2):191-198.

39. Mu F, Harris HR, Rich-Edwards JW, Hankinson SE, Rimm EB, Spiegelman D, Missmer SA. A Prospective Study of Inflammatory Markers and Risk of Endometriosis. Am J Epidemiol. 2018 Mar 1;187(3):515-522.

40. Nothnick W, Alali Z. Recent advances in the understanding of endometriosis: the role of inflammatory mediators in disease pathogenesis and treatment. F1000Res. 2016 Feb 17;5:F1000 Faculty Rev-186.

41. Young VJ, Brown JK, Saunders PT, Horne AW. The role of the peritoneum in the pathogenesis of endometriosis. Hum Reprod Update. 2013 Sep-Oct;19(5):558-69.

42. Berbic M, Hey-Cunningham AJ, Ng C, Tokushige N, Ganewatta S, Markham R, Russell P, Fraser IS. The role of Foxp3+ regulatory T-cells in endometriosis: a potential controlling mechanism for a complex, chronic immunological condition. Hum Reprod. 2010 Apr;25(4):900-7.

43. Drury JA, Parkin KL, Coyne L, Giuliani E, Fazleabas AT, Hapangama DK. The dynamic changes in the number of uterine natural killer cells are specific to the eutopic but not to the ectopic endometrium in women and in a baboon model of endometriosis. Reprod Biol Endocrinol. 2018 Jul 18;16(1):67.

44. Agostinis C, Balduit A, Mangogna A, Zito G, Romano F, Ricci G, Kishore U, Bulla R. Immunological Basis of the Endometriosis: The Complement System as a Potential Therapeutic Target. Front Immunol. 2021 Jan 11;11:599117.

45. Forster R, Sarginson A, Velichkova A, Hogg C, Dorning A, Horne AW, Saunders PTK, Greaves E. Macrophage-derived insulin-like growth factor-1 is a key neurotrophic and nerve-sensitizing factor in pain associated with endometriosis. FASEB J. 2019 Oct;33(10):1121011222.

46. Ahn SH, Edwards AK, Singh SS, Young SL, Lessey BA, Tayade C. IL-17A Contributes to the Pathogenesis of Endometriosis by Triggering Proinflammatory Cytokines and Angiogenic Growth Factors. J Immunol. 2015 Sep 15;195(6):2591-600.

47. Miller JE, Monsanto SP, Ahn SH, Khalaj K, Fazleabas AT, Young SL, Lessey BA, Koti M, Tayade C. Interleukin-33 modulates inflammation in endometriosis. Sci Rep. 2017 Dec 20;7(1):17903.

48. Sikora J, Mielczarek-Palacz A, Kondera-Anasz Z. Association of the Precursor of Interleukin- $1 \beta$ and Peritoneal Inflammation-Role in Pathogenesis of Endometriosis. J Clin Lab Anal. 2016 Nov;30(6):831837.

49. Becker CM, D'Amato RJ. Angiogenesis and antiangiogenic therapy in endometriosis. Microvasc Res. 2007 Sep-Nov;74(2-3):121-30.

50. Dziunycz P, Milewski Ł, Radomski D, Barcz E, Kamiński P, Roszkowski PI, Malejczyk J. Elevated ghrelin levels in the peritoneal fluid of patients with endometriosis: associations with vascular endothelial growth factor (VEGF) and inflammatory cytokines. Fertil Steril. 2009 Dec;92(6):1844-9.

51. Miller EJ, Fraser IS. The importance of pelvic nerve fibers in endometriosis. Womens Health (Lond). 2015 Aug;11(5):611-8.

52. Lessey BA, Young SL. What exactly is endometrial receptivity? Fertil Steril. 2019 Apr;111(4):611-617.

53. Rakhila H, Bourcier N, Akoum A, Pouliot M. Abnormal Expression of Prostaglandins E2 and F2 $\alpha$ Receptors and Transporters in Patients with Endometriosis. Biomed Res Int. 2015;2015:808146.

54. Donnez J, Donnez O, Orellana R, Binda MM, Dolmans MM. Endometriosis and infertility. Panminerva Med. 2016 Jun; 58(2):143-50.

55. Donaghay M, Lessey BA. Uterine receptivity: alterations associated with benign gynecological disease. Semin Reprod Med. 2007 Nov;25(6):461-75.

56. Palomo J, Dietrich D, Martin P, Palmer G, Gabay C. The interleukin (IL)-1 cytokine family - Balance between agonists and antagonists in inflammatory diseases. Cytokine. 2015 Nov;76(1):25-37.

57. Arend WP, Palmer G, Gabay C. IL-1, IL-18, and IL-33 families of cytokines. Immunol Rev. 2008 Jun;223:20-38. 
58. Boraschi D, Italiani $P$, Weil S, Martin MU. The family of the interleukin-1 receptors. Immunol Rev. 2018 Jan;281(1):197-232.

59. Cayrol C, Girard JP. IL-33: an alarmin cytokine with crucial roles in innate immunity, inflammation and allergy. Curr Opin Immunol. 2014 Dec;31:31-7.

60. Hardman C, Ogg G. Interleukin-33, friend and foe in type-2 immune responses. Curr Opin Immunol. 2016 Oct;42:16-24.

61. Hardman CS, Panova V, McKenzie AN. IL-33 citrine reporter mice reveal the temporal and spatial expression of IL-33 during allergic lung inflammation. Eur J Immunol. 2013 Feb;43(2):488-98.

62. Talabot-Ayer D, Lamacchia C, Gabay C, Palmer G. Interleukin-33 is biologically active independently of caspase-1 cleavage. J Biol Chem. 2009 Jul 17;284(29):19420-6.

63. Kondo Y, Yoshimoto T, Yasuda K, Futatsugi-Yumikura S, Morimoto M, Hayashi N, Hoshino T, Fujimoto J, Nakanishi K. Administration of IL-33 induces airway hyperresponsiveness and goblet cell hyperplasia in the lungs in the absence of adaptive immune system. Int Immunol. 2008 Jun;20(6):791-800.

64. Kuessel L, Wenzl R, Proestling K, Balendran S, Pateisky P, Yotova 1st, Yerlikaya G, Streubel B, Husslein H. Soluble VCAM-1/soluble ICAM-1 ratio is a promising biomarker for diagnosing endometriosis. Hum Reprod. 2017 Apr 1;32(4):770-779.

65. Roberts M, Luo X, Chegini N. Differential regulation of interleukins IL-13 and IL-15 by ovarian steroids, TNF-alpha and TGF-beta in human endometrial epithelial and stromal cells. Mol Hum Reprod. 2005 Oct;11(10):751-60.

66. Rižner TL. Diagnostic potential of peritoneal fluid biomarkers of endometriosis. Expert Rev Mol Diagn. 2015 Apr;15(4):557-80

67. Attar E, Bulun SE. Aromatase and other steroidogenic genes in endometriosis: translational aspects. Hum Reprod Update. 2006 Jan-Feb;12(1):49-56.

68. Bulun SE. Endometriosis. N Engl J Med. 2009 Jan 15;360(3):268-79.

69. Grandi G, Mueller MD, Papadia A, Kocbek V, Bersinger NA, Petraglia $F$, Cagnacci A, McKinnon B. Inflammation influences steroid hormone receptors targeted by progestins in endometrial stromal cells from women with endometriosis. J Reprod Immunol. 2016 Sep;117:30-8.

70. Zhang C, Yuan X, Zhang Y. The co-expression of GPER and Gankyrin in ovarian endometriosis and its correlation with the rASRM stages. Arch Gynecol Obstet. 2016 Jan;293(1):133-141.

71. Heublein S, Vrekoussis T, Kuhn C, Friese K, Makrigiannakis A, Mayr $D$, Lenhard M, Jeschke U. Inducers of G-protein coupled estrogen receptor (GPER) in endometriosis: potential implications for macrophages and follicle maturation. J Reprod Immunol. 2013; 97: 95-103.

72. Wang XQ, Yu J, Luo XZ, Shi YL, Wang Y, Wang L, Li DJ. The high level of RANTES in the ectopic milieu recruits macrophages and induces their tolerance in progression of endometriosis. $\mathrm{J} \mathrm{Mol}$ Endocrinol. 2010 Nov;45(5):291-9.

73. Chowdhury I, Banerjee S, Driss A, Xu W, Mehrabi S, Nezhat C, Sidell $\mathrm{N}$, Taylor RN, Thompson WE. Curcumin attenuates proangiogenic and proinflammatory factors in human eutopic endometrial stromal cells through the NF-kB signaling pathway. J Cell Physiol. 2019 May;234(5):6298-6312.

Conflict of interest: none declared Financial support: none declared
74. Ahn SH, Monsanto SP, Miller C, Singh SS, Thomas R, Tayade C. Pathophysiology and Immune Dysfunction in Endometriosis. Biomed Res Int. 2015;2015:795976.

75. Khizroeva J, Nalli C, Bitsadze V, Lojacono A, Zatti S, Andreoli L, Tincani A, Shoenfeld Y, Makatsariya A. Infertility in women with systemic autoimmune diseases. Best Pract Res Clin Endocrinol Metab. 2019 Dec;33(6):101369.

76. Greenbaum H, Weil C, Chodick G, Shalev V, Eisenberg VH. Evidence for an association between endometriosis, fibromyalgia, and autoimmune diseases. Am J Reprod Immunol. 2019 Apr;81(4):e13095.

77. Selam B, Kayisli UA, Garcia-Velasco JA, Arici A. Extracellular matrix-dependent regulation of Fas ligand expression in human endometrial stromal cells. Biol Reprod. 2002 Jan;66(1):1-5.

78. Izumi G, Koga K, Takamura M, Makabe T, Satake E, Takeuchi A, Taguchi A, Urata Y, Fujii T, Osuga Y. Involvement of immune cells in the pathogenesis of endometriosis. J Obstet Gynaecol Res. 2018 Feb;44(2):191-198.

79. Liu Y, Liang S, Yang F, Sun Y, Niu L, Ren Y, Wang H, He Y, Du J, Yang J, Lin J. Biological characteristics of endometriotic mesenchymal stem cells isolated from ectopic lesions of patients with endometriosis. Stem Cell Res Ther. 2020 Aug 8;11(1):346.

80. Liu E, Nisenblat V, Farquhar C, Fraser I, Bossuyt PM, Johnson N, Hull ML. Urinary biomarkers for the non-invasive diagnosis of endometriosis. Cochrane Database Syst Rev. 2015 Dec 23;2015(12):CD012019.

81. Bianco B, André GM, Vilarino FL, Peluso C, Mafra FA, Christofolini $\mathrm{DM}$, Barbosa CP. The possible role of genetic variants in autoimmune-related genes in the development of endometriosis. Hum Immunol. 2012 Mar;73(3):306-15.

82. Sapkota Y, Steinthorsdottir V, Morris AP, Fassbender A, Rahmioglu N, De Vivo I, Buring JE, Zhang F, Edwards TL, Jones S, O D, Peterse D, Rexrode KM, Ridker PM, Schork AJ, MacGregor S, Martin NG, Becker CM, Adachi S, Yoshihara K, Enomoto T, Takahashi A, Kamatani Y, Matsuda K, Kubo M, Thorleifsson G, Geirsson RT, Thorsteinsdottir U, Wallace LM; iPSYCH-SSI-Broad Group, Yang J, Velez Edwards DR, Nyegaard M, Low SK, Zondervan KT, Missmer SA, D'Hooghe T, Montgomery GW, Chasman DI, Stefansson K, Tung JY, Nyholt DR. Meta-analysis identifies five novel loci associated with endometriosis highlighting key genes involved in hormone metabolism. Nat Commun. 2017 May 24;8:15539.

83. Taylor HS, Giudice LC, Lessey BA, Abrao MS, Kotarski J, Archer DF, Diamond MP, Surrey E, Johnson NP, Watts NB, Gallagher JC, Simon JA, Carr BR, Dmowski WP, Leyland N, Rowan JP, Duan WR, Ng J, Schwefel B, Thomas JW, Jain RI, Chwalisz K. Treatment of Endometriosis-Associated Pain with Elagolix, an Oral GnRH Antagonist. N Engl J Med. 2017 Jul 6;377(1):28-40.

84. Singh SS, Suen MW. Surgery for endometriosis: beyond medical therapies. Fertil Steril. 2017 Mar;107(3):549-554.

85. Guo SW. Recurrence of endometriosis and its control. Hum Reprod Update. 2009 Jul-Aug;15(4):441-61. 